\title{
peri-operative care series
}

Consent is a process and not a one-off signature on a form. All too often surgical consent is left to the most junior member of the team. However, current guidance states that the person obtaining consent must either be able to undertake the procedure him or herself, or at least be trained in advising the patient about the procedure.

Additionally, many of us consent patients on the day of the procedure. By this time most arrangements for their procedure are in place and patients will 'go with the flow' despite any doubts they may have. At this stage of the process, they are under duress. Hence David Bogod's article on consent for the surgeon is one that should leave us reflecting on our practice at a time when medical litigation is increasing and patients want to be part of the decision-
making process.

David is a Consultant Anaesthetist at Nottingham City Hospital with an interest in medico-legal matters and consent issues. He is the previous Editor-in-Chief of Anaesthesia, the official journal of the Association of Anaesthetists of Great Britain and Ireland, and was the Chair of the obstetric subcommittee of the World Federation of Societies of Anaesthesiologists.

JYOTI SHAH

Associate Editor

\section{Consent}

David Bogod

Consultant Anaesthetist, Nottingham University Hospitals NHS Trust

\section{CORRESPONDENCE TO}

David Bogod, Consultant Anaesthetist, Nottingham University Hospitals NHS Trust, Hucknall Road, Nottingham NG5 1PB

E: david.bogod@nottingham.ac.uk

\section{Question}

An elderly patient is referred from a nursing home for consideration for hip replacement. Although surgery would benefit both her pain and mobility, you are concerned that her level of dementia means that she is unable to understand the risks and benefits of the procedure. Her daughter wants you to operate and offers to sign the consent form on behalf of her mother. Is the patient able to make the decision to go ahead herself? If not, is the daughter's consent valid? How else might you go about seeking approval to carry out the surgery?

For consent to treatment to be valid, a patient must have sufficient information and understanding to be able to make the decision and must not be under undue influence.

\section{Sufficient information}

Obtaining valid consent to medical treatment protects the practitioner from the crime and tort of battery, ie nonconsensual touching of another person. There are some circumstances where treatment can be administered nonconsensually, primarily in situations in which the patient is not competent to consent (eg while unconscious). In such cases, protection against a charge of battery is afforded by the common law principle of necessity, which is discussed in more detail below, with respect to capacity.

To provide protection against the tort of battery it is only necessary for the person to consent in the broadest terms to the proposed procedure. However, for patients to reach a valid decision as to whether to accept the advice of their medical practitioners, they must be informed of the material risks and benefits which that decision will entail. Failure to provide such information means that patients might make decisions that would run contrary to what they would have done had they been fully apprised of the facts. Should harm then ensue as a result of this decision, they may have a claim against the clinical staff and/or the hospital in negligence.

To make a successful claim in negligence relating to consent, patients have to demonstrate that, had they been informed of the risk, they would not have chosen to undergo the treatment. However, in a recent UK case, the House of Lords reached the view that a woman's autonomy had been so harmed by her surgeon's failure to warn her of the risk of nerve damage after spinal surgery that she was entitled to 
compensation even though knowledge of this risk would not have altered her decision to go ahead with the surgery. ${ }^{1}$ This judgment has led to a far greater emphasis being placed on the provision of information to patients.

How much information should be provided? UK courts have traditionally taken a rather paternalistic view, ruling that this should be judged against what the reasonable doctor would normally be expected to disclose, rather than what the reasonable patient might expect to hear. Recently, courts have tended to move towards a more patient-centred, USA-style approach and a 2001 court of appeal judgment, which stated that it will normally be the responsibility of the doctor to inform a patient of 'a significant risk which would affect the judgment of a reasonable patient', reflects current thinking. This approach is more in keeping with the recommendations of professional bodies., ${ }^{2,5}$

In practice the decision as to what information must be imparted is a complex one, which must be based on the severity of the risk, the likelihood of it occurring, and the individual concerns and priorities of the patient. Rules based on frequency alone ('a risk of more than $1 \%$ must be mentioned') therefore have little, if any, legal standing. Thus, anaesthetists routinely warn patients undergoing perioperative epidural analgesia of the risk of permanent nerve damage, even though the incidence of this is estimated as being between 1 in 6,000 and 1 in 12,000.

Information leaflets for patients are increasingly available, usually published by professional bodies and often in multiple languages. Although these do not replace the need for a face-to-face discussion of risks and benefits, they can be useful adjuncts. Documenting the provision of such a leaflet provides good evidence that an acceptable level of explanation was given.

Once given, consent is regarded as valid no matter how much time has passed, unless new circumstances arise that would require further explanation (for example, new evidence about the risks and benefits of the procedure). However, it is good practice to confirm consent on or close to the day of the procedure. This allows patients time to ask any questions that have occurred to them since the original consultation.

\section{Capacity}

To be competent to consent to a procedure, patients must be able to comprehend and retain the information they have been given, weigh it in the balance to arrive at a decision and then be able to communicate that decision.

Incapable adult patients have until recently been in something of a legal vacuum in England, since no one could consent on their behalf. The defence of necessity (see above) protected clinicians from a charge of battery against such patients and was determined by the patient's 'best interests'. This is a concept that goes beyond the narrow boundaries of medical best interests and incorporates social and financial considerations.

New legislation in the UK has attempted to address this impasse. ${ }^{4}$ The Mental Capacity Act gives legal standing to advance directives, allows competent patients to nominate another person to make healthcare decisions on their behalf should they become incapable and formalises the appointment of independent mental capacity advocates to act on behalf of incapable patients. It also imposes a duty on those caring for such a patient to take all practicable steps to promote capacity and reminds them that, if a patient makes an unwise decision, this should not be regarded per se as indicating incapacity. Indeed, 'the patient's right of choice exists whether the reasons for making that choice are rational, irrational, unknown or even non-existent'. ${ }^{5}$

\section{Coercion}

Patients are often supported by their partners or other family members who understandably want to ensure best treatment and will often tend to act as an advocate. This situation, which must be carefully guarded against, is more likely to arise when patients come from a culture in which the husband is the public face of a family or where the woman has language difficulties. In some circumstances it may be necessary to ask the partner to leave the room during a consultation or to seek a consultation in a different environment. In particular, family members or friends should not act as interpreters for patients.

\section{Written or verbal consent?}

The insistence that patients sign a formal statement to confirm what information they have been given does not in itself improve the consent process. Such documents exist primarily to protect doctors against a claim - often made many years after the event - that the patient was not warned about a risk that materialised (eg dural puncture during an epidural procedure). Such protection can equally well be afforded by the doctor making a contemporaneous note of the information that he has given the patient. However, the default position in all UK hospitals is to seek signed consent for surgical procedures.

This article is based on a lecture and abstract to the European Society of Regional Anaesthesia \& Pain Therapy, 2008.

\section{References}

1. Chester v Afshar [2004] UKHL 41 (http://www.publications.parliament.uk/pa/ Id200304/Idjudgmt/jd041014/cheste-1.htm).

2. Department of Health. Reference guide to consent for examination or treatment, 2nd edn. London: DH; July 2009 (http://www.dh.gov.uk/en/ Publicationsandstatistics/Publications/PublicationsPolicyAndGuidance/ DH_103643).

3. General Medical Council. Good Medical Practice. London: GMC; 2006 [updated 2009] (http://www.gmc-uk.org/static/documents/content/GMP_0910.pdf).

4. Mental Capacity Act 2005. London: Crown copyright; 2006 (http://www.justice. gov.uk/guidance/mental-capacity.htm).

5. Re T (Adult: Refusal of Medical Treatment) [1992] 4 All ER 649, CA. 
$>\quad$ Failure to provide sufficient information to a patient when seeking consent can result in a claim in negligence.

$>\quad$ When determining what information to provide, you should be guided by what this particular patient needs to know in order to make an informed decision.

$>\quad$ Adult patients must be assumed to have capacity to give or withhold consent unless they are clearly unable to comprehend, retain or weigh in the balance the necessary information.

$>$ Adults without capacity come under the protection of the Mental Capacity Act (Adults with Incapacity (Scotland) Act in Scotland). As a result, they may when competent have nominated someone to make healthcare-related decisions on their behalf.

$>$ If nobody has been appointed in this way by a patient it may be necessary to consult an independent mental capacity advocate.

$>$ An adult with capacity has the right to refuse treatment on rational grounds, irrational grounds or, indeed, no grounds at all. 